\title{
The effects of overproduction of two Agrobacterium tumefaciens T-DNA auxin biosynthetic gene products in transgenic petunia plants
}

\author{
Harry J. Klee, Robert B. Horsch, Maud A. Hinchee, Mich B. Hein, ${ }^{1}$ and Nancy L. Hoffmann
}

Monsanto Company, Biological Sciences Department, St. Louis, Missouri 63198 USA

Two genes of Agrobacterium tumefaciens encode enzymes that together produce indoleacetic acid (IAA). The first gene, iaaM, encodes tryptophan monooxygenase which converts tryptophan to indoleacetamide (IAM). The second gene, $\mathbf{i a a H}$, encodes indoleacetamide hydrolase which converts IAM to IAA. We have engineered each of the two genes to be expressed at either high constitutive levels or in a tissue-specific manner. These chimeric genes were introduced separately into petunia plants. The transgenic plants with the Agrobacterium iaaH gene are morphologically normal but have gained the ability to use IAM as an auxin. The plants with iaaM, in contrast, are morphologically abnormal. The observed abnormalities are consistent with an overproduction of auxin and ethylene. These plants contain an approximately 10-fold excess of IAA. The consequences of this deliberate manipulation of the normal phytohormone balance in transgenic plants are described.

[Key Words: Auxin; Agrobacterium; T-DNA; phytohormones; transgenic plants]

Received November 4, 1986; accepted December 6, 1986.

Recent advances in plant transformation and regeneration technology make plants ideal subjects for studying the interactions of different organs and cell types in a developmental system. Plants consist of a large number of distinct tissues and organs. The coordination of these many tissue types as a unit and the continuous development of new organs requires a complex system of communication. Several classes of phytohormones, including the cytokinins and auxins, can greatly influence the patterns of differentiation. The ability to manipulate the relative levels of phytohormones and observe the consequent effects would be extremely useful in elucidating the roles of these compounds in the processes of differentiation.

Agrobacterium tumefaciens is the causative agent of crown gall disease, a neoplastic growth that affects many dicotyledonous plant species. It has been demonstrated that Agrobacterium transfers a portion of its DNA, the T-DNA, to the plant where it is integrated into plant nuclear DNA (for a review, see Fraley et al. 1986). Expression of several genes in the T-DNA results

1Present address: Research Institute of Scripps Clinic, Department of Molecular Biology, La Jolla, California 92037 USA. in tumor formation. These genes were initially identified by transposon mutagenesis of the T-DNA region (Holsters, et al. 1980; Garfinkel et al. 1981; Ooms et al. 1981). There are three T-DNA genes that affect the concentration of the phytohormones auxin and cytokinin in transformed tissue. Tumors induced by wild-type Agrobacterium contain high concentration of both cytokinin and auxin relative to untransformed callus. Bacteria with mutations in one of the genes, $t m r$, cause tumorous growths with a proliferation of roots. Hormone analysis of the transformed tissue shows a high concentration of auxin [indoleacetic acid (IAA)] and essentially wild-type levels of cytokinin (Akiyoshi et al. 1983). On the other hand, bacteria with mutations in either the tms 1 or tms 2 gene induce tumors with a proliferation of shoots. This tissue contains high concentrations of cytokinin but wild-type concentrations of auxin. These results indicate that the T-DNA genes encode enzymes involved in biosynthesis of cytokinin or auxin.

Many recent investigations have demonstrated the biochemical basis of these observations. The tmr gene has been shown conclusively to be involved in cytokinin synthesis (Akiyoshi et al. 1984; Barry et al. 1984; Buchmann et al. 1985). This gene encodes the enzyme that catalyzes the condensation of AMP and isopentenyl py- 
rophosphate to form isopentenyl AMP and has been named isopentenyl transferase (ipt). The pathway of auxin biosynthesis has also been elucidated. The tms 1 and tms2 genes act sequentially to convert tryptophan to indole-3-acetamide (IAM) and then to indole-3-acetic acid (IAA). The tms1 gene carries out the first step and has been named tryptophan monooxygenase (iaaM) (Thomashow et al. 1986). The tms2 gene carries out the second step and has been named indoleacetamide hydrolase (iaaH) (Shroder et al. 1984; Thomashow et al. 1984). It is interesting to note that although this IAA pathway has been elucidated in another bacterium, Pseudomonas sarastanoi (Kosuge et al. 1966), it is not believed to be utilized by plants. Barring that plants contain a generalfunction amide hydrolase, indoleacetamide should be innocuous to plants. Indeed, it has been demonstrated that plants containing the tms1 gene with its own transcriptional promoter do not show abnormal morphology (Follin et al. 1985), although they accumulate indoleacetamide.

It should now be possible to express the T-DNA-derived phytohormone biosynthetic genes in a specific spatial or temporal manner to understand how these hormones regulate plant growth and differentiation. This paper describes the effects on the phenotype of plants transformed with the T-DNA genes involved in auxin biosynthesis.

\section{Results}

\section{Constitutive expression of iaaM in plants}

Agrobacterium synthesizes IAA from tryptophan by a two-step reaction using IAM as an intermediate. Since it is believed that plants do not utilize this pathway in their IAA synthesis, we assumed that the gene encoding the first step in the pathway, iaaM, would not produce an aberrant phenotype unless the plant also contained the gene for the second step, iaaH. Since the wild-type tms1 gene has no apparent phenotypic effect in transformed tobacco plants (Follin et al. 1985), we chose to overproduce the iaaM protein further by fusing the gene to the cauliflower mosaic virus (CaMV) 19S promoter. The normal promoter for this gene in the T-DNA is extremely weak, producing less than $0.001 \%$ of the total polyadenylated plant RNA (Klee et al. 1984). The 19S promoter, in contrast, was expected to express the gene to at least 100 -fold higher levels.

The 19S/iaaM construction (pMON518; Fig. 1) was introduced into petunia by the leaf disc procedure and transformed, kanamycin-resistant callus was obtained. The shoots regenerated from this callus displayed extremely abnormal morphology (Fig. 2). The leaves were much smaller and narrower than wild-type leaves and showed extreme curling. Some, although not all, of the regenerated shoots were covered with roots. In some cases these adventitious roots emanated from the abaxial sides of the leaves. When the shoots were transferred to soil they continued to exhibit an abnormal phenotype. The plants were apically dominant, showing very little branching. The plants continued to show the abnormal leaf morphology and stems were elongated and appeared woody.

Selfed progeny of pMON518 transgenic plants showed abnormal morphologies similar to parental plants. Anatomical comparisons were made between transgenic progeny and wild-type petunia plants. Leaf curling in transgenic plants was the result of greater tissue volume on the adaxial half of the leaf relative to the abaxial half. All cell types in transgenic leaves, with the exception of the abaxial epidermis, were larger than in wild-type leaves (Table 1). The adaxial epidermis and palisade mesophyll were especially enlarged. Intercellular spaces in transgenic leaves showed a similar increase in size. The increased transgenic cell and intercellular space size resulted in a leaf thicker than the wild-type.

Stem anatomy and morphology also differed significantly between transgenic and wild-type plants. The stems of transgenic plants produced more secondary xylem and phloem cells than did wild-type plants of the same age (Fig. 3). In addition, some of the transgenic stems produced numerous adventitious roots which initiated from phloem parenchyma. Relatively normal root primordia formed (Fig. 4A), but, as the root developed, abnormal root apical meristem organization occurred (Fig. 4B). This resulted in aborted root apices after emergence from the stem (Fig. 4C). Another anatomical feature of transgenic stems was cortical hyperplasia (Fig. 4D).

\section{Quantitation of IAM and IAA in transformed plants}

To confirm this hypothesis, auxin levels of the transformed plant tissues were determined. The result of this analysis confirmed that the plants contained very high levels of IAM. Analysis of three independent transformed plants showed IAM concentrations between 2.8 and $25 \mu \mathrm{g} / \mathrm{g}$ fresh weight of leaf tissue (Table 2). This was in contrast to undetectable levels of IAM in wildtype tissue $(<1 \mathrm{pg} / \mathrm{g}$ fresh weight). The leaf tissue of the transformed plants also contained higher levels of IAA. While transformed tissue contained 110-120 ng/g fresh weight of IAA, control tissue contained only about 10 ng/g fresh weight.

It is particularly interesting to note that the plants transformed with pMON518 are fertile. Greater than $90 \%$ of the seed germinated and the abnormal phenotype was stably inherited in the progeny. Thus, the obvious imbalances in auxin and ethylene had no effect on germination of the mature seeds.

\section{Regulated expression of the iaaM gene}

Upon observation of the abnormal phenotype of the pMON518-transformed plants, we decided to put the iaaM gene under the control of a tissue-specific promoter, the soybean $7 \mathrm{~S}$ storage protein promoter. The $7 \mathrm{~S}$ promoter has been shown to be properly regulated in petunia plants (Beachy et al. 1985). The 7 S transcript is un- 
Klee et al.
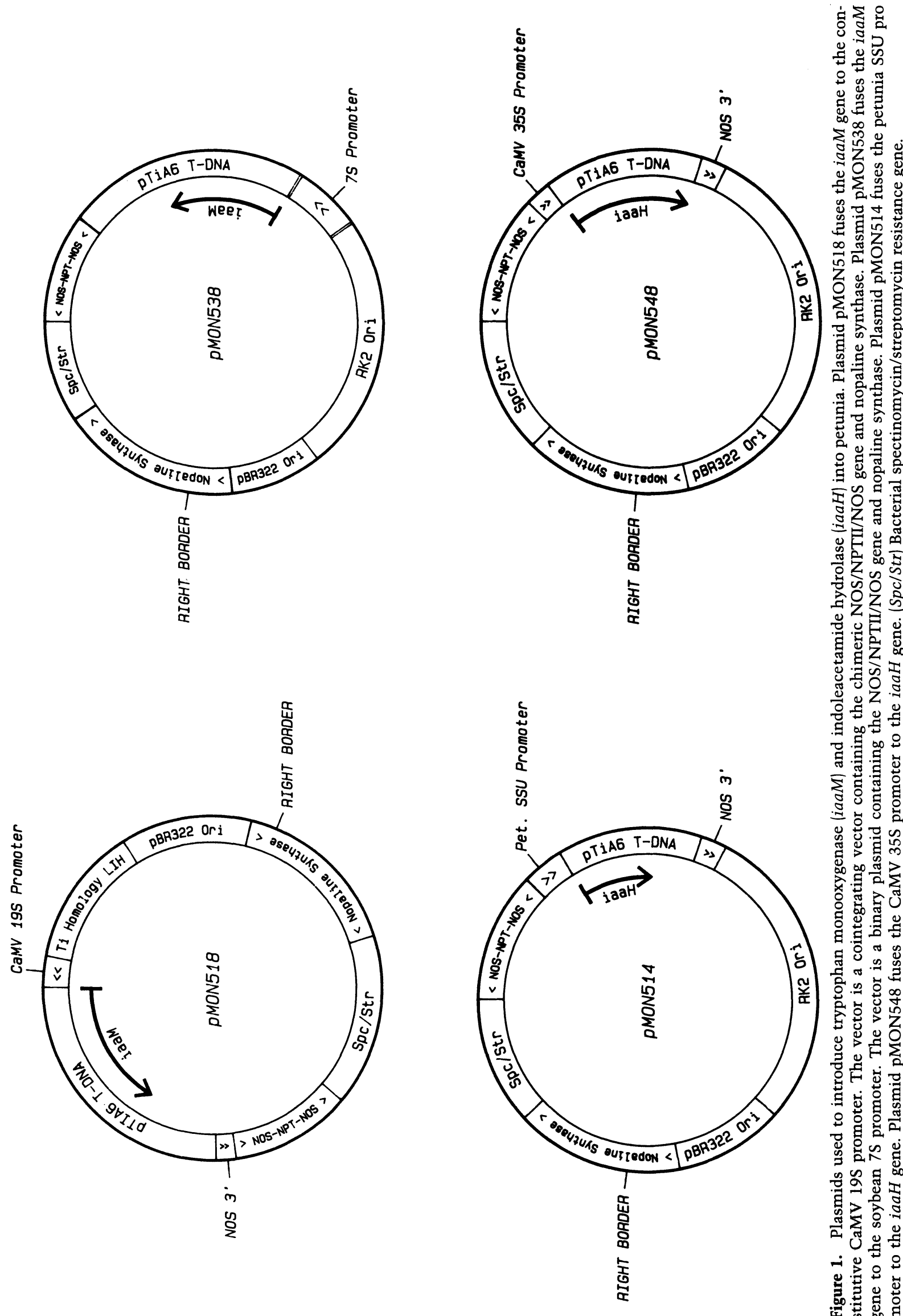
Downloaded from genesdev.cshlp.org on April 26, 2023 - Published by Cold Spring Harbor Laboratory Press

Overproduction of auxins in transgenic plants
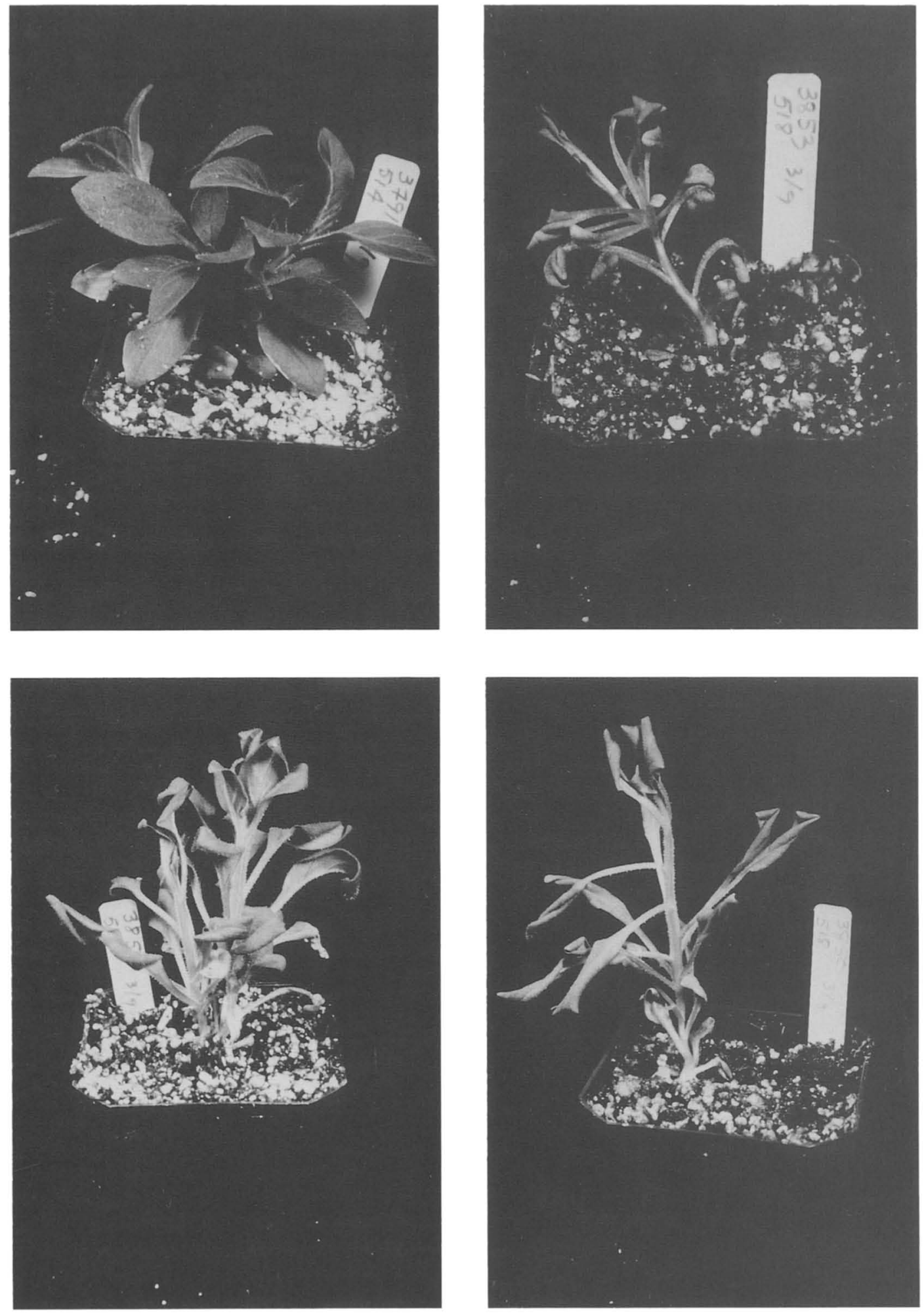

Figure 2. Regenerated petunia plants transformed with either pMON51+ upper left) or pMON5ls, demonstrating the abnormal morphology of plants containing the constitutively expressed iau. gene. The pMON51+ plant is morphologically indistinguishable from a wild-type plant 
Table 1. Sizes in micrometers of the upper and lower epidermi, palisade and spongy mesophyll, and intervening intercellular spaces in 19S/iaaM and wild-type petunia leaves

\begin{tabular}{|c|c|c|c|c|c|c|c|c|c|c|}
\hline & \multicolumn{2}{|c|}{ Upper epidermi } & \multicolumn{2}{|c|}{ Palisade } & \multirow{2}{*}{$\begin{array}{l}\text { Palisade } \\
\text { intercellular space }\end{array}$} & \multicolumn{2}{|c|}{ Spongy } & \multirow{2}{*}{$\begin{array}{l}\text { Spongy } \\
\text { intercellular space }\end{array}$} & \multicolumn{2}{|c|}{ Lower epidermis } \\
\hline & $\overline{\mathrm{L}}$ & $\mathrm{W}$ & $\mathrm{L}$ & $\mathrm{W}$ & & $\mathrm{L}$ & $\mathrm{W}$ & & $\overline{\mathrm{L}}$ & $\bar{W}$ \\
\hline \multicolumn{11}{|c|}{ VR WT } \\
\hline$x$ & 49.3 & 27.3 & 42.1 & 20.0 & 30.5 & 36.3 & 22.0 & 37.7 & 34.8 & 20.9 \\
\hline S.E. & 3.1 & 1.6 & 1.5 & 0.8 & 1.6 & 1.3 & 1.2 & 2.5 & 2.0 & 1.9 \\
\hline \multicolumn{11}{|c|}{ 19S/iaaM } \\
\hline$x$ & 85.6 & 47.3 & 83.2 & 33.6 & 61.5 & 54.5 & 31.9 & 64.4 & 41.2 & 20.6 \\
\hline S.E. & 5.0 & 2.9 & 2.9 & 1.0 & 2.9 & 2.0 & 1.7 & 3.4 & 2.2 & 2.1 \\
\hline
\end{tabular}

Mean and associated standard errors result from 30 independent measurements in each cellular category. Specific details on how the measurements were done are in Materials and Methods.

detectable in leaves and accumulates in immature embryos 10-15 days following pollination. The 7S/iaaM construction, pMON538, was transformed into petunia and the transformed callus was regenerated to plants. The transformed shoots that were obtained initially ex-

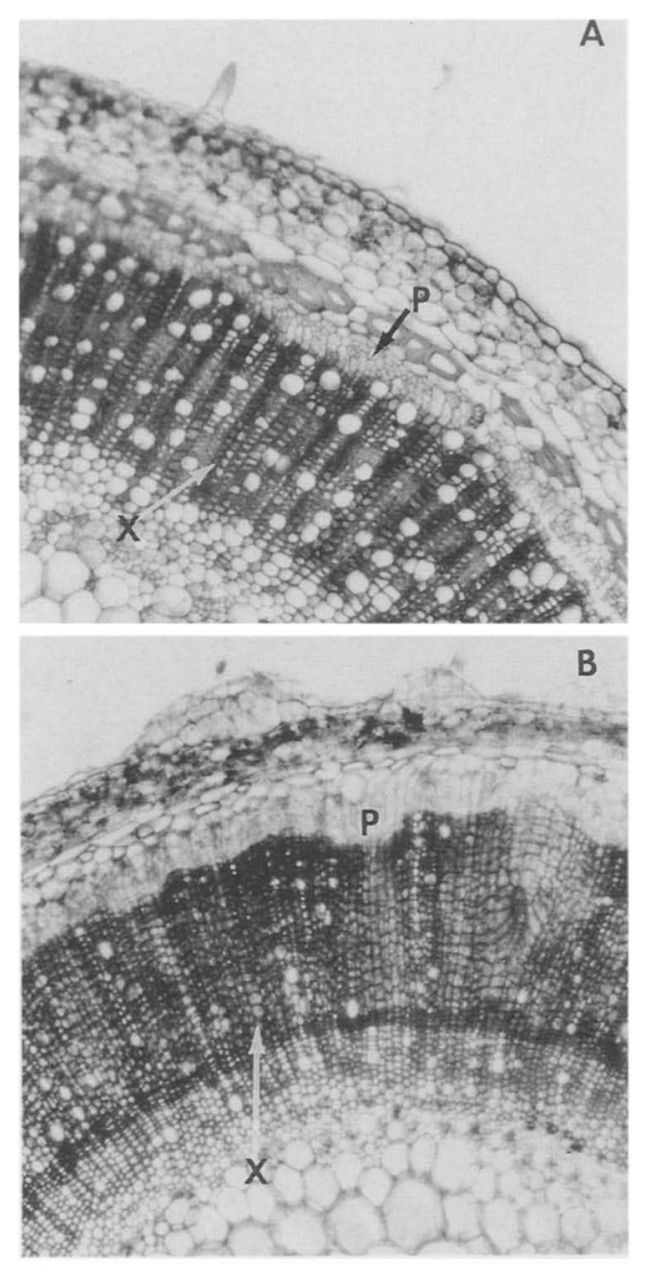

Figure 3. (A) Free-hand cross section of the sixth internode above the crown of a 6-month-old wild-type stem stained with Toluidine Blue. (X) Xylem; (P) phloem. Magnification, $35 \times .(B)$ Free-hand cross section of the sixth internode above the crown of a 6-month-old 19S/iaaM transformant. Magnification, $29 \times$. hibited the same phenotype as the pMON518-transformed plants. However, they soon outgrew the abnormal phenotype (Fig. 5). This is most likely due to expression of the gene at a significant level in transformed callus but proper regulation of the gene following organogenesis. We have observed a similar pattern of $7 \mathrm{~S}$ promoter expression in plant tissue transformed with a 7S/ isopentenyl transferase construction (H. Klee, unpubl.). Expression of the 7S/iaaM gene in developing embryos appeared not to be lethal, since progeny of the transgenic plants showed normal mendelian inheritance for the gene and were normal in appearance. However, this is not surprising since the level of maximal expression of this chimeric gene was approximately the same as that of the constitutive $19 \mathrm{~S}$ promoter, which was clearly not lethal.

\section{Expression of iaaH in plants}

If plants do not normally contain IAM, the presence of the $i a a H$ gene alone in transformed plant tissue should not cause a noticeable auxin-induced alteration in morphology. We have constructed plasmids that fuse the $i a a H$ open reading frame (ORF) to a petunia small-subunit promoter (pMON514; Fig. 1) and to the CaMV 35S promoter (pMON548; Fig. 1). Both of these promoters result in relatively high constitutive expression, both far stronger than the normal iaaH T-DNA promoter (Klee et al. 1984). In neither case are any obvious morphological alterations observable in the transformed, regenerated plants.

One significant difference between wild-type petunia tissue and tissue transformed with pMON514 or pMON548 is an increased responsiveness to IAM as an auxin. We chose to use a more chemically stable IAM analog, naphthalene acetamide (NAM), in our experiments. When leaf discs from regenerated plants are placed on MS medium containing $5 \mu \mathrm{M}$ NAM as the only hormone, the $i a a H$ tissue grows well, producing callus and roots (Fig. 6). The control tissue, in contrast, does not grow at all. It has been reported that the iaaH gene product is capable of converting naphthalene acetamide to naphthalene acetic acid (NAA) in vitro (Kemper et al. 1985) and these results confirm that result in vivo.

High levels of auxins are known to be inhibitory to 

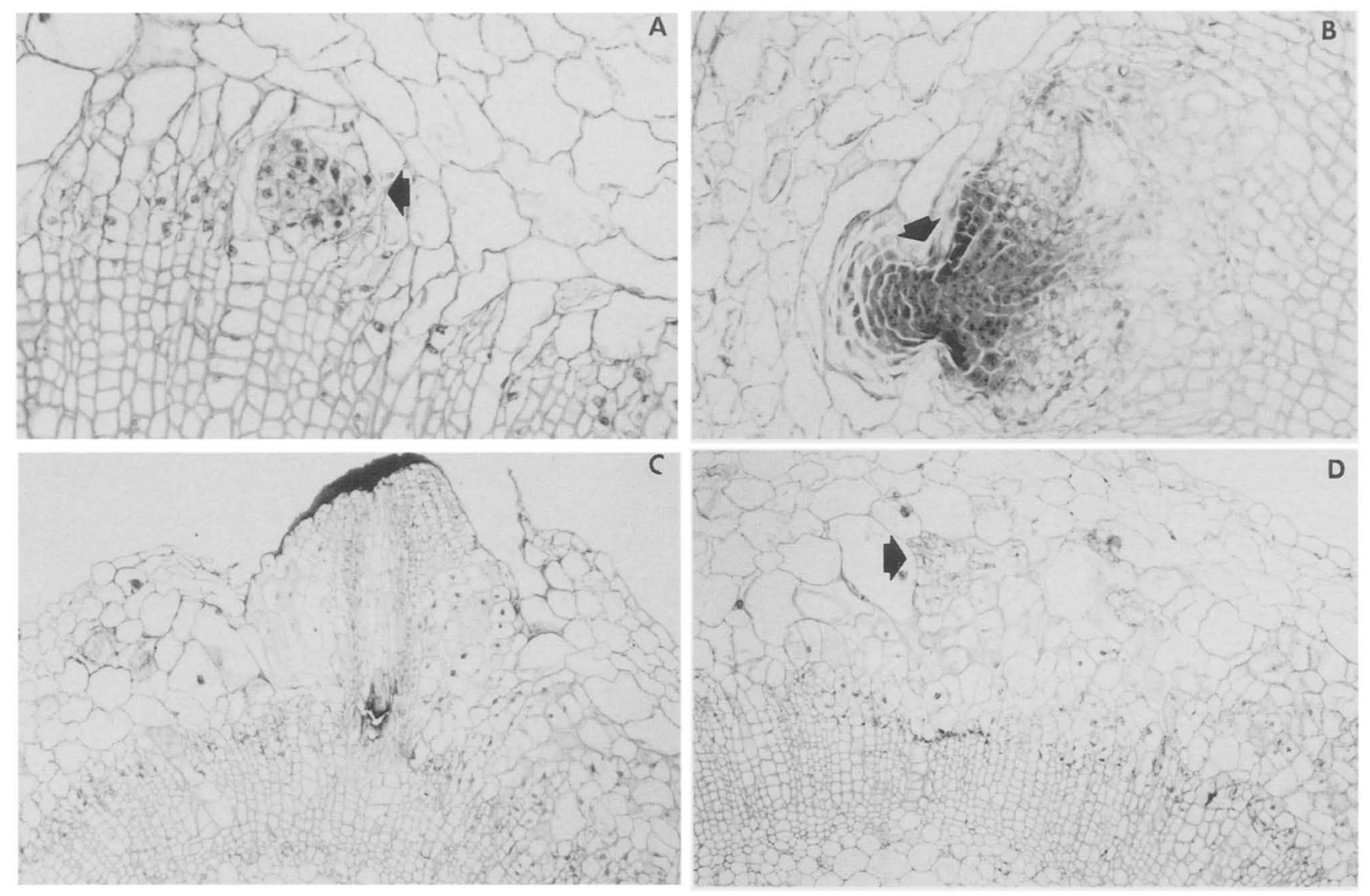

Figure 4. Cross sections of the stem of a 19S/iaaM transgenic petunia plant stained with safranin-fast green. $(A)$ Adventitious root initiation (arrow) by phloem cells. Magnification, 176.$(B)$ Abnormal root apical meristem organization in a median longitudinal section of an adventitious root primordium. Note the pinched region (arrow). Magnification, $140 \times .(C)$ Median longitudinal section of an adventitious root with a necrotic apex. Magnification, $45 \times$. (D) Cell hyperplasia (arrow) in the cortex. Magnification, $45 \times$.

plant growth (see Thimann 1963). Since transformed tissue containing the iaaH gene is capable of converting IAM/NAM to IAA/NAA, this tissue should be more sensitive to NAM than wild-type tissue. A titration of wild-type and pMON514-transformed tissue on MS medium (Gibco) containing B5 vitamins, 3.0\% sucrose,

Table 2. Determination of IAM levels in transformed petunia tissue

\begin{tabular}{llc}
\hline Plant & Plasmid & Concentration \\
\hline 3850 & pMON518 & 6.6 \\
3851 & pMON518 & 25.0 \\
& & 2.8 \\
3853 & pMON518 & 20.4 \\
& & 10.2 \\
3534 & pMON200 & $<0.006$ \\
\hline
\end{tabular}

Plasmid pMON518 contains a 19S/iaaM gene fusion. Plasmid pMON200 is a control, containing only the vector. Values for IAM are presented as $\mu \mathrm{g} / \mathrm{g}$ fresh weight of leaf tissue. Details of the analytical procedure are provided in Materials and Methods.
$0.8 \%$ agar, $0.1 \mu \mathrm{g} / \mathrm{ml} \mathrm{NAA,} \mathrm{and} 1.0 \mu \mathrm{g} / \mathrm{ml}$ benzyladenine and supplemented with 1.0-100 $\mu \mathrm{M}$ NAM showed that the pMON514 tissue was far more sensitive to the NAM. At $30 \mu \mathrm{M}$ NAM, wild-type tissue was growing very well but 514 tissue was severely inhibited (Fig. 7). At $100 \mu \mathrm{M}$ NAM, wild-type tissue was alive but inhibited while 514 tissue was killed. Thus, the presence of the $i a a H$ gene can be correlated to an increased sensitivity to what would normally be only a very weak auxin.

\section{Discussion}

Auxin is essential for plant growth and development. No auxin-less mutants have even been recovered, and mutants with reduced auxin sensitivity are severely abnormal (Mirza et al. 1984; Kelly and Bradford 1986). Exogenous application of micromolar amounts of auxins can cause dramatic changes in plant growth and millimolar concentrations are lethal. In tissue culture, auxins are routinely used to control morphogenic responses.

Plant tissues respond to critical concentrations and to gradients of auxin. Production of auxin in the shoot apex suppresses growth of lateral buds, controlling the shape 


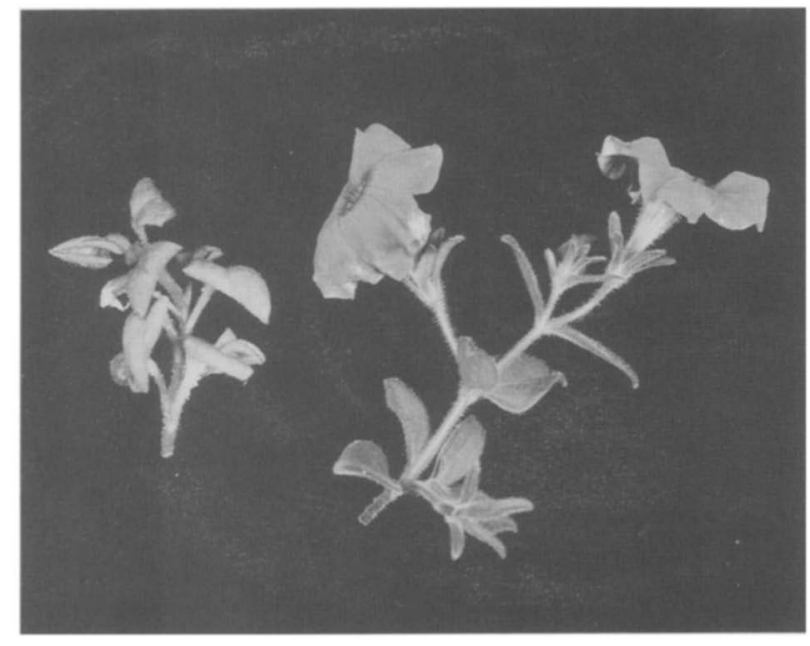

Figure 5. Two shoots from the same plant transformed with the 7S/iaaM gene fusion illustrating the outgrowth of the abnormal morphology as the plant matures. The shoot on the left grew out shortly after the plant was placed in soil while the shoot on the right grew out approximately 2 months later.

and branching habit of plants. Auxin gradients cause growth differentials that result in bending of plant stems and roots to keep plants oriented toward sources of light and gravitational force.

It has been very difficult to study the mechanism of auxin action, even at a gross morphological level, because of problems with uptake and transport of exogenously applied auxins. Many studies have utilized excised segments for response measurements to minimize transport problems, but this is an artificial system that disrupts the influences of other organs.

This paper describes a new approach to the study of auxin involvement in plant development. We have produced transgenic petunia and tobacco plants that over- produce IAA 10-fold in all organs of the plant. This avoids the problems inherent in exogenous application and use of excised tissues.

The overproduction of auxin in plants transformed with the Agrobacterium tumefaciens iaaM gene was surprising. The gene has been shown to encode an enzyme, tryptophan monooxygenase, which converts tryptophan to indoleacetamide (Thomashow et al. 1986). IAM is a compound that is not believed to be a normal plant auxin intermediate (Zenk 1961). It has been demonstrated that expression of the wild-type iaaM gene does not lead to altered morphology or elevated levels of IAA in tobacco (Follin et al. 1985). Since the normal transcriptional promoter is extremely weak in plants (Klee et al. 1984), we fused the iaaM gene to a strong, constitutive promoter element, the $19 \mathrm{~S}$ promoter of CaMV. This promoter is at least 100 times stronger and will thus lead to a much higher level of expression of the iaaM transcript. Consistent with this expectation, the level of accumulated IAM in our transformed petunia plants was about 1000-fold higher than the level reported in tobacco transformed with the wild-type gene.

Although all of the work presented here was done with petunia, it is important to note that we have seen a very similar phenotype in pMON518-transformed tobacco plants (data not shown). Thus, this phenomenon is not peculiar to petunia and demonstrates that it is the gross overproduction of the tryptophan monooxygenase that is responsible for the phenotype.

The higher level of auxin in transformed plants may result from conversion of the extremely high level of IAM to IAA by endogenous plant enzymes. If the $K_{\mathrm{m}}$ of such an endogenous enzyme for IAM is sufficiently high, the lower level of expression by the wild-type T-DNA gene promoter may not have produced enough IAM to show the abnormal phenotype. It has been reported that plant extracts are capable of converting exogenously supplied IAM to IAA, even though this compound is not normally a substrate (Wightman 1986).
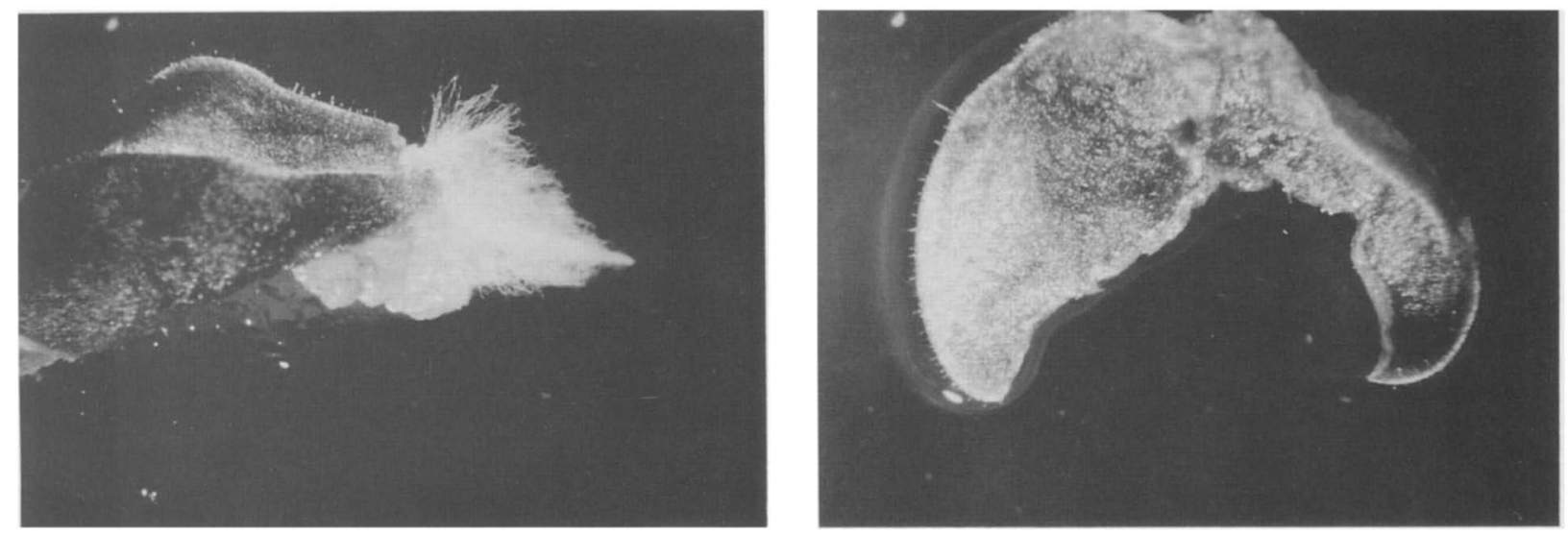

Figure 6. (A) Leaf disc from petunia plant transformed with pMON514 (SSU/iaaH) grown for 14 days on MSO medium supplemented with $5 \mu \mathrm{M}$ NAM as the sole phytohormone. (B) Leaf disc from wild-type petunia plant treated exactly as in $A$. 
An alternative explanation may be that IAM is inherently unstable in plants and is spontaneously hydrolyzed to IAA. Again the level of IAM produced by the wildtype gene might not be high enough to alter the plant phenotypically. Yet another possible explanation of the abnormal phenotype is that the IAM itself acts as an auxin. It has been reported that IAM has an auxin effect, but the data are difficult to interpret since IAM may be converted or spontaneously broken down to IAA (Wightman 1962). Since expression of high levels of $\mathrm{iaaH}$ does not noticeably alter the phenotype of transformed plants lacking the iaaM gene, it seems likely that petunia does not normally produce IAM as an auxin intermediate.

The phenotypic properties of the 19S/iaaM-transformed plants are consistent with the expected constitutive expression of the gene, so that most of the cells in the plant are overproducing an auxin. Unbroken shoot apical dominance is a feature of the petunia transgenic plants, and exogenous auxin has been shown to inhibit lateral bud growth indirectly by maintaining primary shoot apical dominance (Phillips 1975). In our experiments, the shoot apical dominance is so complete that lateral buds remain dormant for several months following removal of the shoot apex. Production of auxin in the apex of wild-type shoots suppresses the growth of lateral buds. Removal of the shoot apex normally results in the outgrowth of the lateral buds within days. This indicates that auxin transport and/or an associated gradient is involved in maintaining apical dominance. Our data suggest that it is the absolute auxin concentrations encountered by a lateral bud that control its ability to grow.

The 19S/iaaM transgenic plants produced approximately twice the number of secondary xylem and phloem cells as did wild-type plants. Exogenous applications of IAA have been shown to increase the number of secondary xylem cells in petioles and stems (Hess and Sachs 1972; Meicenheimer and Larson 1985).

The downward curling of the leaf blade exhibited by the transgenic plants was shown to be the result of increased cell and tissue volume in all cell layers except the abaxial epidermis. Such unequal growth in plant organs is termed epinasty, and epinastic effects, as described above, have been attributed to elevated concentrations of the auxin IAA and of ethylene (Goodwin et al. 1978). Ethylene synthesis in plants is stimulated by exogenous auxin application (Fuchs and Leiberman 1968), and at times it is difficult to determine whether auxin or ethylene plays a primary role in some morphogenic phenomena. Specific events such as cell enlargement, as exhibited in 19S/iaaM adaxial epidermis and mesophyll tissues, can be directly correlated to auxin concentrations (Penny and Penny 1978).

The auxins, indole-butyric acid (IBA) and NAA, are commonly used to stimulate adventitious rooting in stem cuttings (Hartman and Kester 1975). However, it is very unusual for adventitious roots to form on the stems of intact petunia plants. The large number of adventitious root primordia we observed on the 19S/iaaM trans-

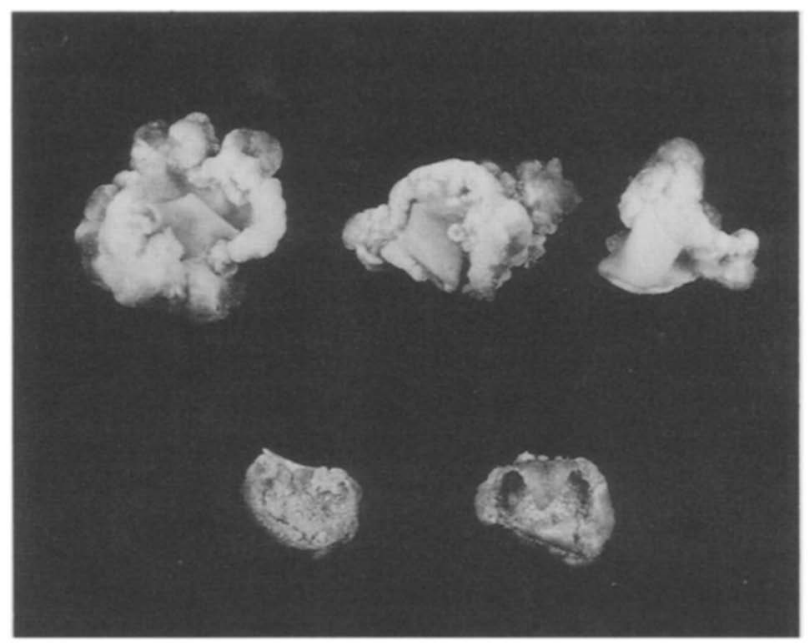

Figure 7. A comparison of petunia leaf discs grown on MS104 medium supplement with $30 \mu \mathrm{M}$ NAM for 18 days. (Top) Wildtype discs; (bottom) discs transformed with pMON514.

genic plants initiated in a region typical for that of adventitious roots in cuttings (Esau 1977). However, the subsequent development of 19S/iaaM adventitious roots did not follow the same development pattern as described for normal adventitious roots (Fabijan et al. 1981). Most of the transgenic adventitious roots were incapable of organizing a complete root apical meristem prior to emergence from the stem and ultimately aborted development. This unusual abortion phenomenon may be related to overproduction of auxin in the organizing tissues of the root as the root may be a normal site for auxin biosynthesis (Feldman 1980).

The transgenic petunia plants described in this work have a number of distinct morphological abnormalities that can be attributed either directly or indirectly to constitutive auxin overproduction. What is remarkable about this work is that these plants nonetheless undergo a complete life cycle. Although auxin is essential to normal growth of a plant, there is a significant tolerance to perturbation of the endogenous auxin level of that plant. The 10-fold increase in endogenous IAA levels and the resultant morphological changes do not prevent growth or affect reproductive capacity. In other words although a number of cell and tissue types are very sensitive to variation in auxin concentrations, most of the cell types are essentially unaffected. Through these experiments we can begin to define relative sensitivities of different cells and tissues to auxin. There could be a number of reasons why certain cells are unaffected by auxin. While each cell is presumably synthesizing the iaaM gene product and, thus, IAA, there will probably be differences in the cells' capacity to inactivate IAA through either conjugation or oxidation. Different cell types might also have very different intracellular concentrations of a "receptor" that could be necessary for mediating auxin effects. What actually defines the relative sensitivities of various cell types to auxin remains an intriguing question. 
The work presented here demonstrates that the normal growth pattern of the plant can be significantly altered by endogenous production of phytohormones that is not homeostatically regulated. There is a large body of literature describing the effects of exogenous applications of hormones to plant tissue. Such experiments have provided the rationale for many of the current hypotheses of phytohormone action, but it is obvious that such an approach is somewhat limited compared with controlled, endogenous regulation of these compounds. Our approach eliminates the important, uncontrolled variables of uptake and transport to the tissue being examined. Endogenous alteration also allows us to examine effects of altered hormone levels in an intact plant rather than excised segment. This allows for examination of hormone-induced effect in the hormonal and nutritional contexts of the whole plant. The phenotypes of the plants described in this work are correlated with the presence and activity of genes that lead to the production of auxin. Although some of the observed morphological changes may not be due to auxin directly, it can be concluded that the increased level of auxin has begun a cascade of events leading to the observed phenotypic properties. This new approach of controlled endogenous production of phytohormones will certainly lead to a greater understanding of the role of auxin in plant morphogenesis and growth. Furthermore, the overproduction of phytohormones in specific tissues or in response to defined stimuli should provide a unique opportunity to examine the expression of genes known to be regulated by phytohormone levels.

\section{Materials and methods}

All cloning and DNA manipulations were performed using Escherichia coli JM101 (Yanisch-Perron et al. 1985). All plasmids used for plant transformations were mobilized into Agrobacterium containing pTiT37-SE, a disarmed nopalinetype Ti plasmid (S. Rogers et al. 1987). Mobilizations were performed using the helper plasmid pRK2013 (Ditta et al. 1980).

\section{iaaM gene expression vectors}

The iaaM gene was cloned in multiple steps from pTiA6 into the multilinker of pUC19 (Yanisch-Perron et al. 1985) in a manner that introduced a unique $\mathrm{XbaI}$ site 18 nucleotides upstream of the translational start codon. This plasmid, pMON517, was used as a precursor for several further constructions. The open reading frame encoding the iaaM gene from pMON517 was introduced into two plant transformation vectors as a $3.5-\mathrm{kb} \mathrm{XbaI}$ fragment. The first of these was the vector pMON237, which contains the promoter for the CaMV $19 S$ promoter (Rogers et al. 1987). The resulting plasmid was designated pMON518 (Fig. 1). The second construction was with pMON529 (H. Klee, unpubl.), a vector containing the promoter for the soybean $\alpha^{\prime}$-subunit of $\beta$-conglycinin (Beachy et al. 1985), creating pMON538 (Fig. 1).

\section{iaaH gene expression vectors}

The HindIII fragment from nucleotides 3390 to 5512 (Barker et al. 1983) of pTiA6 containing the entire iaaH ORF was cloned into M13 mp8. This clone was then modified by site-directed mutagenesis (Zoller and Smíth 1983) to introduce a unique BamHI site 10 nucleotides upstream of the translational start. The mutated gene was then cloned into pUC19 to create pMON544. The ORF encoding the iaaH gene from pMON544 was fused to the CaMV $35 \mathrm{~S}$ promoter in the transformation vector pMON530 (Rogers et al. 1987). This plasmid was designated pMON548 (Fig. 1). A second plasmid, pMON514, fusing the promoter of a petunia ribulose-1,5-bisphosphate carboxylase small-subunit gene, ssu11A (Tumer et al. 1986), to the $\mathrm{iaaH}$ at -35 with respect to the transcriptional start site was also constructed.

\section{Introduction of genes into plants}

Agrobacterium strains containing the transforming vectors were used to transform Petunia hybrida VR (Wallroth et al. 1986) leaf discs by the procedure of Horsch et al. (1985). Transformed tissue was selected for resistance to kanamycin and transformed plants were obtained from this transformed tissue for each plasmid construction. The transformed plants were examined for the presence of T-DNA by Southern blot analysis (Southern 1975).

\section{Assay of IAM and IAA acid}

Levels of IAM and IAA were assayed in extracts of leaf tissue by HPLC with amperometric and fluorometric detection. Individual frozen leaves of petunia plants were extracted by grinding with a glass pestle in $1.5-\mathrm{ml}$ microfuge tubes containing cold $\left(-20^{\circ} \mathrm{C}\right) 80 \%$ aqueous methanol with $10 \mathrm{mg} /$ liter butylated hydroxytoluene and $500 \mathrm{mg} /$ liter citrate. After the initial extraction, the particulate plant material was collected by centrifugation $(13,000 \mathrm{~g}, 10 \mathrm{~min})$ and extracted again. The supernatants from the consecutive extractions were pooled and reduced to the aqueous phase under reduced pressure. IAM and IAA were separated from the plant extract by reversed-phase HPLC on $\mu$ Bondapak C18 (Waters Associates, $7.6 \mathrm{~mm} \times 300$ $\mathrm{mm})$. Samples were separated by gradient elution $(0-20 \% \mathrm{~B}$, in $25 \min ; \mathrm{A}=0.05 \mathrm{M}$ sodium phosphate $\mathrm{pH} 3.0, \mathrm{~B}=\mathrm{CH}_{3} \mathrm{CN}$; flow rate $=4.0 \mathrm{ml} / \mathrm{min}$ ) and collected individually into silanized glass tubes and reduced to the aqueous phase under reduced pressure. IAM and IAA were analyzed by HPLC using sequential detection (Hein et al. 1984) with amperometry (glassy carbon, +0.990 volts versus $\mathrm{Ag} / \mathrm{AgCl}$ ) and fluorometry (254 nm excitation, $340 \mathrm{~nm}$ emission) after separation on Biophase C8 $(4.2 \mathrm{~mm} \times 25 \mathrm{~cm})$ with $0.04 \mathrm{M} \mathrm{KHPO}_{4}-(\mathrm{pH} 5.7)$ in $13 \%$ methanol at $50^{\circ} \mathrm{C}$. The response ratio of the detectors to peaks eluting at the $k^{\prime}$ of IAA or IAM were used to assess peak purity. If the detectors' response ratio was not identical to that of authentic standards, data were discarded (Hein et al. 1984). Recovery of IAA from plant tissue was estimated by determining recovery of a $\left[2-{ }^{-14} \mathrm{C}\right] \mathrm{IAA}$ internal standard $(500 \mathrm{dpm}$; $650 \mathrm{dpm} / \mathrm{ng}$; Amersham) by scintillation counting of the HPLC effluent. The internal standard was added to each sample immediately after extraction.

\section{Anatomical observations}

Stems and leaves of wild-type and transformed plants were either sectioned free-hand or prepared for paraffin microtomy by fixing in formalin/acetic acid/alcohol (FAA), dehydrating in a tertiary butyl alcohol sequence, and embedding in Paraplast. Paraplast-embedded material was cut at $10 \mu \mathrm{m}$ and stained with safranin-fast green. Free-hand sections were stained with $0.05 \%$ (aq.) Toluidine Blue. 


\section{Cell measurements}

Cell measurements were made using a calibrated ocular micrometer on 30 independent, randomly chosen paraffin sections of leaves of a 19S/iaaM plant and a wild-type of identical ages. The length of the adaxial (upper) and abaxial (lower) epidermal cells was measured on the axis parallel to the leaf surface, and the cell width was measured on the perpendicular axis. The palisade mesophyll cell length was measured along the axis perpendicular to the leaf surface, and the width measured along the axis perpendicular to that of the length. The spongy mesophyll length was measured along the longest axis of the cell and width was measured in the widest region along an axis perpendicular to the length. The palisade and spongy mesophyll intercellular spaces were measured as the distance between two adjacent cells along an axis parallel to the leaf surface.

\section{Acknowledgments}

We greatly appreciate the continuing support and suggestions of Rob Fraley and Steve Rogers, and we would like gratefully to acknowledge Roger Beachy for the $7 \mathrm{~S}$ promoter and invaluable advice. We would also like to thank Barb Schiermeyer for help in preparation of the manuscript.

\section{References}

Akiyoshi, D., R. Morris, R. Hinz, B. Mischke, T. Kosuge, D. Garfinkel, M. Gordon, and E. Nester. 1983. Cytokinin/auxin balance in crown gall tumors is regulated by specific loci in the T-DNA. Proc. Natl. Acad. Sci. 80: 407-411.

Akiyoshi, D., H. Klee, R. Amasino, E. Nester, and M. Gordon. 1984. T-DNA of Agrobacterium tumefaciens encodes an enzyme of cytokinin biosynthesis. Proc. Natl. Acad. Sci. 81: 5994-5998.

Barker, R., K. Idler, D. Thompson, and J. Kemp. 1983. Nucleotide sequence of the T-DNA region from the Agrobacterium tumefaciens octopine Ti plasmid pTil5955. Plant Mol. Biol. 2: 335-350.

Barry, G., S. Rogers, R. Fraley, and L. Brand. 1984. Identification of a cloned cytokinin biosynthetic gene. Proc. Natl. Acad. Sci. 81: 4776-4780.

Beachy, R., Z.-L. Chen, R. Horsch, S. Rogers, N. Hoffman, and R. Fraley. 1985. Accumulation and assembly of soybean $\beta$ conglycinin in seeds of transformed petunia plants. EMBO $\mathrm{J}$. 4: 3047-3053.

Buchmann, I., F. Marner, G. Schroder, S. Waffenschmidt, and J. Schroder. 1985. Tumour genes in plants: T-DNA encoded cytokinin biosynthesis. EMBO J. 4: 853-859.

Ditta, G., S. Stanfield, D. Corbin, and D. Helinski. 1980. Broad host range DNA cloning system for Gram-negative bacteria: Construction of a gene bank of Rhizobium meliloti. Proc. Natl. Acad. Sci. 77: 7347-7351.

Esau, K. 1977. Anatomy of seed plants. John Wiley \& Sons, New York.

Fabijan, D., E. Yeung, I. Mukherjee, and D.M. Reid. 1981. Adventitious rooting in hypocotyls of sunflower (Helianthus annuus) seedlings. Physiol. Plant. 53: 578-588.

Feldman, L.J. 1980. Auxin biosynthesis and metabolism in isolated roots of Zea mays. Physiol. Plant. 49: 145-150.

Follin, A., D. Inze, F. Budar, C. Genetello, M. Van Montagu, and J. Schell. 1985. Genetic evidence that the tryptophan 2mono-oxygenase gene of Pseudomonas savastanoi is functionally equivalent to one of the T-DNA genes involved in plant tumour formation by Agrobacterium tumefaciens. Mol. Gen. Genet. 201: 178-185.

Fraley, R., S. Rogers, and R. Horsch. 1986. Genetic transformation in higher plants. CRC Crit. Rev. Plant Sci. 4: 1-45.

Fuchs, Y. and M. Leiberman. 1968. Effects of kinetin, IAA, and gibberellin on ethylene production and their interaction in the growth of seedlings. Plant Physiol. 43: 2029-2036.

Garfinkel, D., R. Simpson, L. Ream, F. White, M. Gordon, and E. Nester. 1981. Genetic analysis of crown gall: Fine structure map of the T-DNA by site-directed mutagenesis. Cell 27: $143-153$.

Goodwin, P.B., B.I. Gollnow, and D.S. Letham. 1978. Phytohormones and growth correlations. In Phytohormones and related compounds-A comprehensive treatise (ed. D.D. Letham, P.B. Goodwin, and T.J.V. Higgins), vol. II. Elsevier/ North-Holland Biomedical Press, New York.

Hartman, H.E. and D.E. Kester. 1975. Plant propagation-principles and practice. Prentice-Hall, Inc., Englewood Cliffs, New Jersey.

Hein, M., M. Brenner, and W. Brun. 1984. Concentrations of abscisic-acid and indole-3-acetic acid in soybean seeds during development. Plant Physiol. 76: 951-954.

Hess, T. and T. Sachs. 1972. The influence of the mature leaf on xylem differentiation. New Phytol. 7: 903-914.

Holsters, M., B. Silva, F. Van Vliet, C. Genetello, M. De Block, P. Dhaese, A. Depicker, D. Inze, G. Engler, R. Villarroel, M. Van Montagu, and J. Schell. 1980. The functional organization of the nopaline $A$. tumefaciens plasmid pTiC58. Plasmid 3: 212-230.

Horsch, R., J. Fry, N. Hoffmann, M. Wallroth, D. Eichholtz, S. Rogers, and R. Fraley. 1985. A simple and general method for transferring genes into plants. Science 227: 1229-1231.

Kelly, M. and K. Bradford. 1986. Insensitivity of the diageotropica tomato mutant to auxin. Plant Physiol. 82: 713-717.

Kemper, E., S. Waffenschmidt, E. Weiler, T. Rausch, and J. Schroder. 1985. T-DNA-encoded auxin formation in crowngall cells. Planta 163: 257-262.

Klee, H., A. Montoya, F. Horodyski, C. Lichtenstein, D. Garfinkel, S. Fuller, C. Flores, J. Peschon, E. Nester, and M. Gordon. 1984. Nucleotide sequence of the tms genes of the pTiA6NC octopine Ti plasmid: Two gene products involved in plant tumorigenesis. Proc. Natl. Acad. Sci. 81: 17281732.

Kosuge, T., M. Heskett, and E. Wilson. 1966. The conversion of L-tryptophan to indole-3-acetamide by an enzyme system from Pseudomonas savastanoi. I. Biol. Chem. 241: 37383744.

Meicenheimer, R.G. and P.R. Larson. 1985. Exogenous auxin and $N$-1-napthylpthalamic acid effects on Populus deltoides xylogenesis. J. Exp. Bot. 36: 320-329.

Mirza, J., G. Olsen, T.H. Iversen, and E.P. Maher. 1984. The growth and gravitropic responses of wild-type and auxin-resistant mutants of Arabidopsis thaliana. Physiol. Plant. 60: $516-522$.

Ooms, G., P. Hooykaas, G. Moolenaar, and R. Schilperoort. 1981. Crown gall plant tumors of abnormal morphology, induced by Agrobacterium tumefaciens carrying mutated octopine $\mathrm{Ti}$ plasmids: Analysis of T-DNA functions. Gene 14: 33-50.

Penny, P. and D. Penny. 1978. Rapid responses to phytohormones. In Phytohormones and related compounds-a comprehensive treatise (ed. D.D. Letham, P.B. Goodwin, and T.J. Higgins), vol. II. Elsevier/North-Holland Biomedical Press, New York.

Phillips, I.D.J. 1975. Apical dominance. Annu. Rev. Plant Physiol. 26: 341-367. 
Klee et al.

Rogers, S.G., H.J. Klee, M.C. Byrne, R.B. Horsch, and R.T. Fraley. 1987. Improved vectors for plant transformation: Expression cassette vectors and new selectable markers. Methods Enzymol. (in press).

Schroder, G., S. Waffenschmidt, E. Weiler, and J. Schroder. 1984. The T-region of Ti plasmids codes for an enzyme synthesizing indole-3-acetic acid. Eur. J. Biochem. 138: 387-391.

Southern, E. 1975. Detection of specific sequences among DNA fragments separated by gel electrophoresis. I. Mol. Biol. 98: $503-517$.

Thimann, K. 1963. Plant growth substances: Past, present and future. Annu. Rev. Plant Physiol. 14: 1-8.

Thomashow, L., S. Reeves, and M. Thomashow. 1984. Crown gall oncogenesis: Evidence that a T-DNA gene from the Agrobacterium Ti plasmid pTiA6 encodes an enzyme that catalyzes synthesis of indoleacetic acid. Proc. Natl. Acad. Sci. 81: 5071-5075.

Thomashow, M., S. Hugly, W. Buchholz, and L. Thomashow. 1986. Molecular basis for the auxin-independent phenotype of crown gall tumor tissues. Science 231: 616-618.

Tumer, N., W.G. Clark, G. Tabor, C. Hironaka, R. Fraley, and D. Shah. 1986. The genes encoding the small subunit of ribulose-1,5-bisphosphate carboxylase are expressed differentially in petunia leaves. Nucleic Acids Res. 14: 3325-3342.

Wallroth, M., A. Gerats, S. Rogers, R. Fraley, and R. Horsch. 1986. Chromosomal localization of foreign genes in Petunia hybrida. Mol. Gen. Genet. 202: 6-15.

Wightman, F. 1962. Metabolism and biosynthesis of 3-indoleacetic acid and related indole compounds in plants. Can. J. Bot. 40: 689-718.

Yanisch-Perron, C., J. Vieira, and J. Messing. 1985. Improved M13 phage cloning vectors and host strains: Nucleotide sequences of the M13mpl8 and pUC19 vectors. Gene 33: $103-119$.

Zenk, M. 1961. 1-Indole-3-acetyl- $\beta$-D-glucose. A new compound in the metabolism of indole-3-acetic acid in plants. Nature 191: 493-494.

Zoller, M. and M. Smith. 1983. Oligonucleotide-directed mutagenesis using M13-derived vectors: An efficient and general procedure for the production of point mutations in any fragment of DNA. Methods Enzymol. 100: 468-500. 


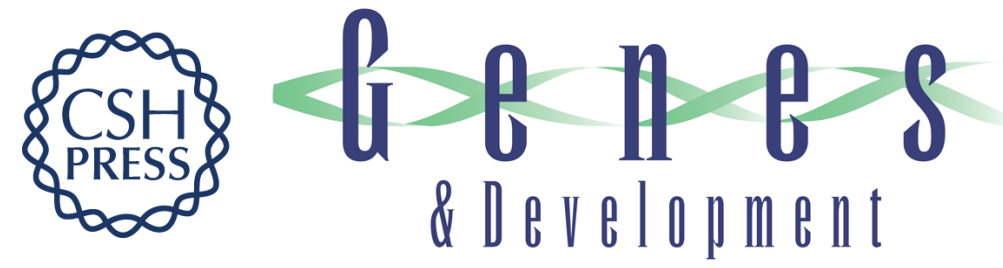

\section{The effects of overproduction of two Agrobacterium tumefaciens T-DNA auxin biosynthetic gene products in transgenic petunia plants}

Genes Dev. 1987, 1:

Access the most recent version at doi:10.1101/gad.1.1.86

References This article cites 36 articles, 12 of which can be accessed free at:

http://genesdev.cshlp.org/content/1/1/86.full.html\#ref-list-1

License

Email Alerting Receive free email alerts when new articles cite this article - sign up in the box at the top Service right corner of the article or click here. 